\title{
O Programa Mais Médicos: controvérsias na mídia
}

\author{
The More Doctors Program: media controversies \\ Vinício Oliveira da Silva', David Ramos da Silva Rios², Catharina Leite Matos Soares³, Isabela \\ Cardoso de Matos Pinto ${ }^{4}$, Carmen Fontes Teixeira ${ }^{5}$
}

DOI: 10.1590/0103-1104201811712

1 Universidade Federal da Bahia (UFBA), Instituto de Saúde Coletiva (ISC) Salvador (BA), Brasil. vinicio_oliveira@hotmail. com

2 Universidade Federal da Bahia (UFBA), Faculdade de Medicina, (FMB) Salvador (BA), Brasil. david-rios@hotmail.com

3 Universidade Federal da Bahia (UFBA), Instituto de Saúde Coletiva (ISC) Salvador (BA), Brasil. catharinamatos@gmail.com

${ }^{4}$ Universidade Federal da Bahia (UFBA), Instituto de Saúde Coletiva (ISC) Salvador (BA), Brasil. isabelacmp@gmail.com

5 Universidade Federal da Bahia (UFBA), Instituto de Humanidades, Artes e Ciências (IHAC) - Salvador (BA), Brasil.

carment@ufba.br
RESUMO Realizou-se um estudo exploratório sobre a repercussão do lançamento do Programa Mais Médicos na mídia, a partir da identificação, da seleção e da análise de notícias publicadas em jornais de circulação nacional, nos sites de Entidades Médicas e nos ligados à Reforma Sanitária Brasileira, no período de lançamento do Programa (julho a setembro de 2013). Procedeu-se à análise de discurso do material selecionado. Os resultados demonstram diferentes filiações políticas das entidades analisadas, com ampla diversidade de opiniões, que se contradizem ou coadunam, contribuindo, assim, para que o tema ganhasse um significado político que ultrapassasse o setor saúde. Apesar de todas as discussões e críticas em torno da implementação do Programa, este representa um grande avanço em termos de política pública, que integra, em uma única proposta, elementos voltados ao provimento emergencial de médicos, à educação médica e ao desenvolvimento da infraestrutura das unidades de saúde no âmbito do Sistema Único de Saúde (SUS). O material analisado evidencia que a mídia atua, simultaneamente, como espaço de reverberação do debate político e, também, como um ator político que influi na opinião pública acerca do Programa.

PALAVRAS-ChaVe Pessoal de saúde. Sistema Único de Saúde. Atenção Primária à Saúde. Saúde pública. Saúde da família.

ABSTRACT An exploratory study about the repercussion of the launching of the More Doctors Program in the media was carried out, through the identification, selection and analysis of news published in national circulation newspapers, on the websites of Medical Entities and related to the Brazilian Health Reform, during the launch period of the Program, July to September 2013. The analysis of discourse of the selected material was carried out. The results show different political affiliations of the analyzed entities, with a wide diversity of opinions, which contradict or contradict each other, thus contributing to the issue gaining a political significance that surpassed the health sector. In spite of all the discussions and criticisms surrounding the implementation of the Program, this represents a major advance in terms of public policy, which integrates, in a single proposal, elements aimed at the emergency provision of doctors, medical education and the development of the infrastructure of the units under Unified Health System (SUS). The material analyzed shows that the media act simultaneously as a space for reverberation of the political debate and also as a political actor that influences public opinion about the Program.

KEYWORDS Health personnel. Unified Health System. Primary Health Care. Public health. Family health. 


\section{Introdução}

Desde sua criação, o Sistema Único de Saúde (SUS), no Brasil, vem enfrentando dificuldades para a sua consolidação, comprometendo a garantia dos seus princípios norteadores, como a universalidade, a equidade e a integralidade. Um dos fatores que contribuem para isso é a vasta extensão territorial, atrelada às diferenças locorregionais, que culminam com a oferta inadequada da atenção à saúde para a população'. A universalização da oferta da atenção à saúde no âmbito do SUS, portanto, impõe ao Estado brasileiro o desafio de desenvolver mecanismos para a resolução de tal questão.

A Estratégia Saúde da Família (ESF) tem sido, desde 1996, a principal estratégia do governo federal para garantir a universalização da atenção à saúde, por meio da expansão da atenção primária. Eixo estruturante do processo de implementação da Política de Atenção Básica à Saúde, a ESF propõe mudanças nas práticas assistenciais e organizativas, traduzidas na maior proximidade com as comunidades, no conhecimento acerca dos problemas de saúde nos territórios de abrangência e no desenvolvimento de intervenções sobre os problemas detectados que contemplem ações promocionais, preventivas, assistenciais e reabilitadoras, tendo em vista garantir a integralidade da atenção nesse nível. Há, também, uma expectativa de que essa estratégia se responsabilize pela coordenação do cuidado dos usuários do SUS, estabelecendo vínculos entre equipes e comunidade e uma maior integração com os diversos níveis de complexidade do sistema de saúde ${ }^{2,3}$, de modo a orientar o processo de organização de redes integradas de atenção à saúde que possibilitem o acesso da população aos serviços, capazes de dar respostas efetivas aos seus problemas de saúde e atender às suas necessidades.

Embora tenha se desenvolvido grande esforço em torno da expansão da ESF, que alcançou números expressivos nos últimos anos, sobretudo a partir de 2003, com o Programa de Expansão e Consolidação da Saúde da Família (Proesf), permanece a dificuldade de fixação de profissionais de saúde nas áreas de acesso mais difícil ${ }^{4}$, especialmente do profissional médico, em decorrência de velhas questões que permeiam o processo de construção do SUS, tais como: precarização do trabalho, no que tange aos vínculos empregatícios e às condições dos serviços; escassez de profissionais em áreas rurais e em municípios distantes das capitais dos estados; problemas crônicos na gestão do trabalho, como, por exemplo, descumprimento de carga horária contratada, incipiência das ações de educação permanente, entre outras questões.

As primeiras estratégias para a superação dessa problemática no Brasil remontam aos anos 1960. Elas se estruturavam na forma de programas governamentais, que visavam a deslocar profissionais de saúde para regiões desprovidas de assistência, como foi o caso do Projeto Rondon (anos 1960-1970) e do Programa de Interiorização das Ações de Saúde e Saneamento (Piass), nos anos 1970. A partir da implementação do SUS, houve vários outros programas, como o Programa de Interiorização do Sistema Único de Saúde (Pisus), o Programa de Apoio Social Especial Integrado ${ }^{6}$, cabendo destacar o Programa de interiorização do Trabalho em Saúde (PITS), implementado em 2001, que visava a melhorar os indicadores de saúde de 150 municípios brasileiros com menos de 50.000 habitantes, que apresentavam uma mortalidade infantil de 80 por mil nascidos vivos, prevalência de doenças como malária, hanseníase e tuberculose, e estavam localizados nas regiões Norte, Nordeste, Centro-oeste e Norte de Minas Gerais?.

Essa estratégia, assim como as demais, que vieram logo em seguida, não apresentou resultados positivos, visto que as ações de interiorização eram pontuais e focavam aspectos quantitativos, negligenciando, portanto, elementos como o processo formativo dos médicos e os aspectos políticos e sociais 
que determinam suas escolhas profissionais. Logo, o problema da má distribuição dos médicos não se restringe apenas ao seu aspecto quantitativo, mas refere-se, também, à qualidade de sua formação e ao modelo norteador da atenção à saúde.

Estudos, como o de Campos e Malik ${ }^{8}$, mostram, ainda, que, mesmo em localidades onde há a presença de médicos, existe alta rotatividade de profissionais que se mostram insatisfeitos com as condições de trabalho. Entre os fatores que apresentariam maior correlação com essa rotatividade, estão: a falta de capacitação para atuar na atenção básica, a distância até o local de trabalho e a falta de materiais nas unidades de saúde para a realização da prática assistencial. Assim, tais aspectos tornam-se um dos principais desafios para a expansão e a qualificação das ações realizadas na ESF, bem como no processo de universalização da saúde.

Devido a tal importância, essa problemática tem sido inserida nas agendas governamentais e tem estado no centro de debates recentes, de políticas e programas, a exemplo do Programa de Valorização de Profissionais da Atenção Básica (Provab) e do Programa 'Mais Médicos' (PMM). Este último, instituído pela medida provisória número 621 , em 8 de julho de 2013, prevê melhorias nas unidades de saúde, estimula o preenchimento de postos de trabalho médico em regiões onde não existem esses profissionais para atuarem na atenção básica, notadamente, nas periferias das grandes cidades e municípios do interior, bem como incentiva mudanças no processo formativo dos futuros médicos ${ }^{9}$.

O lançamento desse Programa gerou grande repercussão entre as Entidades Médicas (EM), cujos posicionamentos reverberaram na mídia institucionalizada e nos veículos de comunicação dessas entidades, a exemplo dos jornais do Conselho Federal de Medicina (CFM), da revista da Associação Médica Brasileira (AMB) e dos boletins da Federação Nacional dos Médicos (Fenam). Esse processo tornou-se, rapidamente, objeto de estudos por parte de vários pesquisadores, a exemplo de Magno ${ }^{10}$, que considera o Programa uma resposta às demandas apresentadas pela população nas jornadas de Junho de 2013, quando, entre as múltiplas reivindicações apresentadas pelas lideranças dos movimentos que foram às ruas das grandes cidades brasileiras, apareceu a crítica e a demanda por mais e melhores serviços de saúde.

A implantação do Programa, por sua vez, fez-se acompanhar de significativa produção bibliográfica, analisada por Rios"1, que aponta os diversos temas abordados nesses trabalhos, entre os quais, destacam-se: a) provimento e fixação de médicos; b) análise política do PMM; c) avaliação do PMM; d) impactos do PMM sobre os modelos de atenção; d) formação médica e supervisão acadêmica; e) PMM na mídia.

Do conjunto de trabalhos analisados (137), apenas sete, publicados entre os anos de 2013 e 2016, tratavam deste último tema, ou seja, da repercussão da polêmica em torno do PMM em jornais e revistas de grande circulação nacional. A maioria dos estudos refere-se à reação de diferentes categorias e atores sociais ao Programa, analisada por meio dos seus discursos em diferentes veículos de comunicação, como a 'Folha de São Paulo', o 'Correio Braziliense'12 ou a revista 'Veja'13; jornais televisivos, como 'Bom Dia Brasil'14, da Rede Globo de Comunicações; sites de internet, como os sites Pragmatismo Político e Portal Médico ${ }^{15}$; bem como nas redes sociais, como o Facebook ${ }^{\mathbf{1 6}}$.

Considerando que uma análise mais abrangente das repercussões do PMM deve buscar informações para além dos veículos da grande mídia, o objetivo deste trabalho é analisar os posicionamentos políticos de EM e da saúde coletiva, diante do lançamento do PMM, através das informações veiculadas nos diferentes meios de comunicação e publicadas em sites oficiais das EM e outras entidades vinculadas ao movimento da Reforma Sanitária Brasileira (RSB). 


\section{O Programa Mais Médicos: estraté- gia de reorganização do mercado de trabalho e da formação médica}

O PMM, criado em julho de 2013 por meio de uma Medida Provisória que, posteriormente, foi convertida em Lei, em outubro do mesmo ano (Lei $n^{0} 12.871$, de 22 de outubro de 2013), faz parte dos chamados 'Pactos em favor do Brasil'11, um conjunto de ações e objetivos que abordaram cinco temas prioritários que estiveram no centro das manifestações de junho de 2013.

Estruturado em três pilares (provimento emergencial de médicos, educação médica e infraestrutura), o PMM busca formar recursos humanos, na área médica, para atuar no SUS, orientando o funcionamento dos cursos de medicina no País e reduzindo as desigualdades regionais na área da saúde, garantindo, assim, um acesso igualitário e integral a todos 9 . A novidade apresentada pelo PMM diz respeito, portanto, à conjugação da proposta de redistribuição dos profissionais médicos com a ênfase atribuída à implementação de mudanças no processo de formação médica, seja através dos programas de residência, seja através do estímulo à introdução de inovações metodológicas nos cursos de graduação.

No que se refere ao provimento médico, o governo dá preferência a profissionais formados no Brasil, contudo, em caso de não preenchimento das vagas, estas são oferecidas a médicos estrangeiros interessados em trabalhar na atenção básica, utilizando uma licença provisória, concedida por um período de três anos, renováveis por mais três. Cabe ressaltar que, segundo o PMM, a concessão de tal licença não requer a realização dos testes de validação do diploma de graduação, mas apresenta uma série de exigências, como a obrigatoriedade de trabalhar em um território específico e em unidades de saúde da ESF? .

O Programa não se esgota nessa medida. Ele busca, ainda, realizar uma avaliação seriada dos graduandos em medicina, ampliar o espaço de temas, como atenção básica e atendimento de urgência e emergência no currículo médico, regular a abertura e a oferta de cursos de medicina, de acordo com critérios definidos pelo Ministério da Saúde e pelo Ministério da Educação, bem como formular novas diretrizes curriculares para os Cursos de Medicina no País?

Destarte, o lançamento desse Programa suscitou debates acalorados, com discursos polêmicos e controversos observados nas entidades de classe da sociedade civil, nas escolas médicas, no âmbito das organizações e conselhos que congregam gestores das instituições públicas de saúde, entre outros, configurando-se, assim, como um dos temas que evidenciam os conflitos que perpassam o debate político atual na área de saúde no Brasil.

\section{Metodologia}

Durante o período de 24 de junho a 30 de setembro de 2013, início do processo de implementação do PPM, foram acessados, diariamente, os sites de três jornais de circulação nacional, quais sejam: 'O Globo' (www. oglobo.com.br), 'Estado de São Paulo' (www. estadao.com.br) e 'Folha de São Paulo' (www. folha.uol.com.br), com o intuito de analisar os posicionamentos políticos de EM e da saúde coletiva que fazem militância em torno do PMM. Simultaneamente, foram visitados, semanalmente, os sites oficiais de três EM: CFM (www.portal.cfm.org.br), AMB (www. amb.org.br) e Fenam (www.fenam.org.br), bem como os sites da Associação Brasileira de Saúde Coletiva (Abrasco) (www.abrasco. org.br) e do Centro Brasileiro de Estudos de Saúde (Cebes) (www.cebes.org.br).

$\mathrm{Na}$ busca dos dados, consideraram-se as notícias nas quais aparecia a expressão 'Mais Médicos'. Como resultado, foram encontrados 86 textos sobre o assunto nos sites dos jornais e das referidas instituições. Posteriormente, utilizou-se o critério de saturação $0^{17}$, como critério de exclusão, 
haja vista que a emissão de opiniões sobre o Programa estava sendo emitida pelas mesmas pessoas em momentos diferentes. Outro critério de exclusão adotado considerou a repetição de conteúdo de algumas notícias, visto que a mesma informação foi veiculada em diferentes locais, a exemplo do Cebes e da Abrasco, caracterizando-as como duplicidade. No total, foram analisadas 29 notícias, por meio da análise do discurso ${ }^{18}$ (tabela 1). As reportagens foram sistematizadas em planilha no Excel $^{\circledR}$, por meio das seguintes categorias: Local de publicação (site); Data da publicação; Título da publicação; Conteúdo da publicação; Os atores sociais e as respectivas entidades que eles representam; Teor do conteúdo da opinião sobre o Programa; e Observações.

Tabela 1. Distribuição das notícias encontradas, segundo fonte de busca

\begin{tabular}{lrr}
\hline Fonte de busca & Encontradas & Analisadas \\
\hline O Globo & 8 & 2 \\
O Estado de São Paulo & 7 & 1 \\
Folha de São Paulo & 10 & 3 \\
Conselho Federal de Medicina - CFM & 19 & 4 \\
Associação Médica Brasileira - AMB & 8 & 2 \\
Federação Nacional dos Médicos - Fenam & 7 & 3 \\
Associação Brasileira de Saúde Coletiva - Abrasco & 13 & 9 \\
Centro Brasileiro de Estudos de Saúde - Cebes & 14 & $\mathbf{2 9}$ \\
\hline TOTAL & $\mathbf{8 6}$ & 5 \\
\hline
\end{tabular}

Após a sistematização dos dados, a análise realizada buscou observar: os posicionamentos das entidades; a sua filiação aos diferentes projetos políticos no campo da saúde ${ }^{19}$; os pontos de concordâncias e discordâncias entre os diferentes atores sociais e entidades, destacando a diversidade de opiniões enunciadas sobre $o$ Mais Médicos e os principais pontos de conflitos que se observam sobre o Programa.

\section{O PMM na mídia: análise dos posicionamentos políticos}

A análise das notícias acerca do Programa evidenciou, em primeiro lugar, que o lançamento do PMM motivou posicionamentos a favor e contra por parte de várias entidades, configurando-se uma polêmica que envolveu instituições governamentais, a exemplo do Ministério da Saúde e do Ministério da Educação, que se aliaram a favor do Programa, e as EM e outras que expressaram pontos de vista distintos.

Os temas que mobilizaram o posicionamento dessas EM foram variados, dada a amplitude e a diversidade de propostas do Programa. A análise de algumas das notícias selecionadas permite, inclusive, identificar uma diferença entre a posição do jornal que veicula a notícia e o posicionamento das entidades. Um exemplo disso foi uma notícia publicada no jornal 'O Globo', que admite que "a iniciativa da presidente demonstra a disposição do governo em buscar melhorias para a área"20, ao tempo em que expõe o posicionamento contrário ao PMM por parte das EM.

O tema mais controverso foi a abertura de postos de trabalho no SUS para médicos estrangeiros, que gerou, por parte das EM, 
uma forte reação contrária, a ponto de ameaçarem o governo com a deflagração de uma 'greve dos médicos', como se evidencia no trecho de reportagem reproduzido a seguir:

[...] a Federação Nacional dos Médicos, o Conselho Federal de Medicina e a Associação Médica Brasileira anunciam [...] um calendário de protestos e uma possível greve dos médicos contra a importação de profissionais ${ }^{20}$.

Como apontado anteriormente, a justificativa apresentada pelo PMM para a contratação de médicos estrangeiros baseia-se na identificação de significativa escassez desses profissionais em algumas regiões e estados do País, principalmente nos municípios de pequeno porte e em áreas periféricas das grandes cidades. Estudos na área de demografia médica ${ }^{\mathbf{2 1}}$ demonstram que há uma desigualdade na distribuição, fixação e no acesso aos médicos no Brasil. A maioria dos profissionais concentra-se nas regiões Sul e Sudeste, nas capitais e nos grandes municípios. Esse problema, entretanto, apresenta-se como uma 'falta' de médico, sendo criticado pela grande mídia, como exemplifica o trecho abaixo, retirado da reportagem publicada na Folha de São Paulo, quando do lançamento do Programa.

Embora sejam inegáveis as dificuldades para conseguir acesso a médicos, as entidades insistem em que esses profissionais não estão em falta. Cabe interrogar por que chegamos a esse ponto, em que lideranças médicas se recusam a enxergar o que está à vista de todos e como interesses corporativos colidem com os públicos e nos colocam à beira de um conflito institucional grave 22 .

É interessante constatar que, apesar da superficialidade da análise apresentada pelo jornal, o trecho evidencia a questão política central envolvida na controvérsia em torno do PMM, ou seja, a colisão entre os interesses corporativos das EM e as necessidades do sistema público de saúde, em termos da expansão da oferta de serviços, que, evidentemente, demanda a contratação e a redistribuição desses profissionais.

Essa questão está associada a outra, que é a revalidação dos diplomas dos médicos estrangeiros que se prontificaram a vir trabalhar no Brasil, processo que implicava a aplicação do Exame Nacional de Revalidação de Diplomas Médicos expedidos por instituição de educação superior estrangeira, que ficou conhecido como Revalida ${ }^{23}$. As EM, em geral, passaram a exigir a realização desse Exame, argumentando que seria uma forma de valorizar os médicos brasileiros, o que parece expressar certa desconfiança de que os estrangeiros teriam mais dificuldade em ser aprovados.

Defendendo-se da possibilidade dessa posição ser interpretada como 'corporativismo', um dos dirigentes do CFM, Aloísio Tibiriçá, comenta, em entrevista, que

As pessoas falam que estamos com uma pauta corporativista, mas o que queremos prezar é pela valorização dos médicos brasileiros e pela qualidade da medicina praticada no país $\mathbf{2 4}$.

O trecho da reportagem, reproduzido a seguir, evidencia claramente a posição do CFM:

[...] o CFM se posicionou contra a vinda destes médicos. No entanto, se esta 'importação' acontecesse, o CFM exigiria que houvesse a aplicação do Revalida [...]24.

O Ministério da Saúde, no entanto, propôs, como uma forma de contornar a exigência do Revalida, diante da urgência com que era proposta a implementação do Programa, o registro provisório dos médicos estrangeiros, que, nessas circunstâncias, poderiam atuar durante um tempo determinado em unidades de saúde específicas nas quais fossem alocados, caso em que o Exame Revalida seria dispensado?.

As entidades vinculadas à RSB, como Cebes e $\mathrm{Abrasco}^{25}$, por sua vez, concordavam 
com a proposta do Ministério da Saúde, discordando da realização do exame sob o argumento de que o Revalida poderia reproduzir certa hegemonia da categoria médica brasileira, na medida em que pressupõe a conformação de uma banca examinadora cuja composição poderia influenciar negativamente a aprovação dos médicos estrangeiros, tanto em função de critérios relativos à competência técnica dos profissionais quanto por razões de caráter ideológico ${ }^{24}$.

No que se refere ao debate em torno da competência técnica dos estrangeiros, é importante registrar o posicionamento de lideranças da Abrasco e do Cebes, que propõem a aplicação do Revalida também para os médicos brasileiros, como se percebe no trecho da reportagem publicada no site da Abrasco, que contém extratos de entrevistas feitas com os presidentes dessas entidades na época:

O presidente da Abrasco [...] entende que esta revalidação deve ser feita tanto para os estrangeiros como para os brasileiros ${ }^{\mathbf{2 4}}$.

Ana Maria Costa avalia o Revalida como uma queda de braço colocada pelo CFM, [...] não entendemos que o Revalida, que é uma prova, possa dar conta de apresentar a realidade do conhecimento e da qualidade destes profissionais $[\ldots]^{\mathbf{2 4}}$.

Essa posição também aparece na fala de um docente do Departamento de Medicina Preventiva da Universidade Federal do Rio de Janeiro (UFRJ), que, em matéria do jornal ' $\mathrm{O}$ Globo', expressou pontos de vista que não se coadunam com aqueles apresentados pelas entidades representativas dos profissionais.

Ter médicos é melhor do que não ter, e é possível e plausível atraí-los para trabalhar em cidades do interior bem como realizar testes, compatíveis com as necessidades do país, para revalidar diplomas de estrangeiros. O Brasil não deve e não precisa se desviar da rota que conduz à organização de um abrangente e sólido sistema

público de saúde para todos ${ }^{26}$.

É importante salientar que, apesar de a direção das entidades ligadas à RSB apoiar o Programa, alguns dos seus dirigentes entendiam que essa era uma medida emergencial e que questões estruturais que perpassam o SUS constituem problemas para o seu desenvolvimento, a exemplo da precariedade dos vínculos e das condições de trabalho em grande parte das unidades que compõem o sistema. De fato, a precariedade dos vínculos, especialmente no âmbito da Atenção Primária à Saúde, já era apontada desde 2001 por estudo financiado pelo Ministério da Saúde, segundo o qual a maioria dos empregos era gerada por meio de contratos precários (temporários irregulares e autônomos prestadores de serviços) ou terceirizada ${ }^{1}$.

Diante disso, dirigentes das entidades ligadas à RSB enfatizam a necessidade de 'carreiras estruturadas', não só para os médicos, mas para todos os trabalhadores do SUS, conforme se apresenta no trecho da notícia reproduzido abaixo:

Segundo a presidente do Cebes, os médicos não são a única categoria de trabalhadores que faltam no interior do Brasil e o plano de carreira para servidores do SUS é uma necessidade de todos os trabalhadores da área. [...]. Precisamos voltar a discutir dois fatores: a questão do plano de cargos e salários e o ato médico [...]. Luis Eugenio, da Abrasco, aponta que [...] tem falta, sobretudo, de carreiras estruturadas ${ }^{\mathbf{2 4}}$.

Esse aspecto também foi objeto de posicionamento por parte das EM, que argumentaram que o possível deficit de médicos na Atenção Primária à Saúde deve-se à precariedade das condições de trabalho e à baixa remuneração, considerando que, por conta disso, os profissionais médicos buscam instalar-se em locais onde o mercado apresenta melhores condições. A precarização dos vínculos de trabalho, expressa na forma de 
contratação dos profissionais do PMM, corresponde, então, ao ponto de concordância entre as entidades analisadas. Todavia, para os dirigentes do Cebes e da Abrasco, esse é um aspecto que não deve inviabilizar a implantação do Programa. Admitem, também, que a contratação de profissionais só terá resultados se estiver aliada a outras medidas, como a melhoria da infraestrutura física, o custeio das unidades e a constituição das redes integradas de atenção à saúde.

Para o presidente da [...] Abrasco, [...] o que este programa prevê é importante, mas não são apenas estas as necessidades do SUS. 'Além da construção, é preciso assegurar o custeio das unidades de saúde, assim como é fundamental organizar as redes integradas de serviços', explica24.

Outro tema presente na polêmica em torno do Programa diz respeito à abertura de vagas e novos cursos de Medicina no País, proposta contida no PMM com a intenção de garantir, em médio e longo prazos, o provimento de médicos, principalmente em regiões e estados em que se verifica maior necessidade de profissionais. Nesse particular, o Ministério da Educação (MEC) se colocou como apoiador do Ministério da Saúde e, por conseguinte, do Programa, no que tange à regulação da abertura de novos cursos de medicina e à ampliação das vagas.

O MEC também mudou as regras de abertura de faculdades de Medicina. O tradicional sistema de balcão foi encerrado e será substituído pelo lançamento de editais ${ }^{20}$.

Curiosamente, entre as reportagens investigadas, não foram encontrados posicionamentos das escolas médicas das universidades brasileiras. Entretanto, em algumas delas, aparece a referência à problemática da política de educação superior no Brasil, ou seja, a ênfase no ensino superior privado em detrimento das universidades públicas ${ }^{27}$. A presidente do Cebes nacional na época, Prof. ${ }^{a}$ Ana Maria Costa, em entrevista concedida ao site da Escola Politécnica de Saúde Joaquim Venâncio (EPSJV), da Fundação Oswaldo Cruz (Fiocruz), chama a atenção para a necessidade de se fortalecer o ensino superior público na área de saúde:

[...] uma medida importante é o fortalecimento das universidades federais, a criação de universidades no interior e a extinção das más escolas de medicina [...], mas a tarefa de fazer valer, avaliar o ensino médico, dentro da perspectiva técnica, ética e política é fundamental24.

No que tange ao possível impacto do PMM sobre a formação médica, aparece, em primeiro lugar, a polêmica em torno da possibilidade de extensão do tempo de duração do curso de Medicina para 8 anos, proposta rejeitada por todas as entidades analisadas. Predomina nas reportagens a discussão da possibilidade da realização dos primeiros anos da residência médica em municípios do interior, que parece ser, para a maioria daqueles que se manifestaram sobre o Programa, uma decisão pertinente, pois se apresenta como oportunidade para conhecimento da realidade de saúde brasileira, bem como a possibilidade de reflexão sobre a própria formação médica, enfatizando-se, inclusive, a necessidade de ampliação das vagas de residência médica nas áreas de saúde da família e comunidade. O presidente da Abrasco, Prof. Luís Eugenio Souza, destaca, por exemplo, a importância da inserção de novos cenários de prática na formação médica, em entrevista concedida à EPSJV, da Fiocruz:

Luis Eugênio, da Abrasco, avalia este programa como uma oportunidade destes profissionais conhecerem a realidade brasileira. Nesse sentido, os estudantes [...] devem ser treinados em outros ambientes, como unidades básicas de saúde nas cidades grandes, médias e pequenas ${ }^{\mathbf{2 4}}$. 
O PMM é visto por esse dirigente, portanto, como uma importante estratégia de expansão da atenção primária, da assistência médica às periferias das grandes cidades e nos municípios do interior dos estados, além de ser uma oportunidade histórica de integração entre os Ministérios da Educação e da Saúde, em uma proposta intersetorial de reorientação da distribuição e da formação médica. Entretanto, cabe ressaltar a crítica feita ao foco dado pelo governo federal ao profissional médico, em detrimento dos outros profissionais de saúde, argumentando-se que muitos países avançaram nos sistemas de saúde por meio da formação de outros profissionais, a exemplo dos agentes comunitários e enfermeiros.

[...] Ilona Kickbusch [...] prevê a necessidade de um novo plano nacional de saúde que desenvolva um sistema mais horizontal, menos focados em médicos [...]. O governo federal precisa agora traçar um plano envolvendo a sociedade civil, as autoridades locais, as associações de profissionais de saúde. [...]. Até porque grande parte dos problemas de saúde do Brasil hoje são doenças crônicas, para as quais o tratamento ou prevenção não necessariamente necessitam de um médico $[\ldots]^{\mathbf{2 8}}$.

Por último, cumpre ressaltar que o fato de o PMM ter sido lançado sem uma discussão mais ampla com organizações da sociedade civil, escolas médicas e outros Ministérios, também consistiu num ponto de discussão em algumas reportagens, como a apresentada a seguir, na qual o diretor de defesa profissional da Associação Paulista de Medicina destaca as 'arbitrariedades' cometidas pelo Programa e as possíveis implicações jurídicas desse fato:

Para o diretor de defesa profissional da Associação Paulista de Medicina (APM), Marun David Cury, o programa deve ser questionado na Justiça por ter 'arbitrariedades', como a mudança na duração do curso de medicina29.

\section{Discussão e conclusões}

Os pontos de vista apresentados pelos atores sociais contemplados neste estudo revelam os posicionamentos político-ideológicos de diferentes entidades, evidenciando, por este ângulo, a existência de um conflito que contrapõe as entidades representativas de diversos grupos de interesse no campo da saúde, organizados e mobilizados em torno da defesa de projetos políticos distintos, os quais se desdobram nos projetos políticos em saúde, isto é, na forma como concebem e se posicionam em torno das estratégias de construção do SUS no País. Tomando como referencial o estudo de Paim ${ }^{19}$, que aponta a existência de três projetos em disputa na área de saúde, quais sejam: o projeto mercantilista, o projeto democrático e o racionalizador, cabe identificar, em primeiro lugar, que o PMM se situa no âmbito do projeto racionalizador, ou seja, o projeto governamental que resulta do esforço de acomodação entre propostas de mudança do modelo de atenção à saúde, com ênfase na expansão da atenção primária, através da ESF, ao tempo em que reproduz o modelo médico-assistencial hegemônico no nível primário de atenção $0^{30}$.

A crítica e as ponderações apresentadas pelas EM e pelas entidades vinculadas ao processo de RSB, por sua vez, são feitas a partir da adesão prévia aos projetos aos quais se filiam, quais sejam, no caso das lideranças da EM, supostamente: o projeto mercantilista $^{31}$, com forte viés corporativo ${ }^{32,33}$, e, no caso das entidades como Cebes e Abrasco, o projeto da RSB. Nessa perspectiva, ganha inteligibilidade a reação das EM ao ingresso de profissionais estrangeiros no mercado de trabalho, posicionamento que expressa uma rejeição a que o Estado passe a regular esse mercado, historicamente sob controle dos próprios profissionais, enquanto, por seu turno, as entidades da RSB apoiam o PMM no que se refere à expansão da oferta de serviços, tendo como imagem-objetivo a universalização, tal como posta na Constituição 
Federal de 1988, ao tempo em que questionam a reprodução do modelo médico-assistencial, visto que defendem a integralidade do cuidado, que exige a implementação de práticas de saúde que extrapolam a assistência médica. Essa polêmica, ou seja, a 'questão médica' de fato evidencia um conflito político central com relação à direcionalidade impressa ao processo de construção do SUS ${ }^{34}$.

Entretanto, é importante enfatizar que a filiação a tais projetos não se dá de forma homogênea entre os membros das entidades, havendo, assim, representantes das EM que defendem e se aproximam do projeto da RBS. Tal diversidade é percebida em menor grau nas entidades do Cebes e da Abrasco ${ }^{35}$.

Além disso, a implantação do PMM acentuou um problema que não se restringe à área de saúde e que diz respeito à Política econômica, no que se refere à geração de emprego e renda, na medida em que fortalece uma tendência que vem sendo observada especialmente no âmbito da administração pública, que diz respeito à flexibilização e à precarização das relações de trabalho, fenômeno que vem se intensificando na área de saúde ${ }^{36}$. Vários estudos apontam que vínculos precários, de modo geral, e, em especial, na ESF, estão associados à maior susceptibilidade do trabalhador da saúde à concorrência danosa entre municípios que têm dificuldade de fixação do profissional e à instabilidade política, gerando alta rotatividade ${ }^{37}$, sendo essa uma dimensão sobre a qual a avaliação do Programa deve se debruçar.

Entretanto, é importante ressaltar que as lacunas deixadas pelo Programa, no que tange à gestão do trabalho, por ora, não representam um empecilho para a sua expansão. Ao contrário, a inserção de profissionais de saúde preparados para a atenção primária incorpora uma dimensão tecnológica que tem como fio condutor as condições imateriais do processo de trabalho na saúde. Isso pode vir a ser um importante elemento, tanto para as políticas de promoção da saúde quanto para a mudança do modelo de atenção.
No que se refere aos obstáculos para a fixação dos médicos em determinadas regiões, embora a infraestrutura de trabalho tenha sido referida por algumas reportagens como um possível limitador, ela representa o problema menos mencionado pelos estudos da literatura, que apontam como os principais condicionantes da atração e fixação desse profissional o nível salarial e o cumprimento da carga horária de 40 horas ${ }^{38,39}$. Nesse particular, trabalhos recentes mencionam que a possibilidade de complementação de salário no nível de urgência e emergência, além da diversificação da prática assistencial, é um imperativo para a fixação dos médicos na ESF em algumas capitais do Brasil, refutando, portanto, a tese de que as condições de trabalho são imperativas para atrair e fixar os médicos a determinadas regiões e áreas do País ${ }^{38}$.

Outro conjunto de opiniões sobre o PMM centra-se na formação médica e na qualidade dos serviços prestados. Apesar das EM salientarem a possível baixa qualidade técnica dos profissionais estrangeiros, o estudo de Madureira ${ }^{40}$ mostra exatamente o contrário, pois, ao estudar o Sistema de Saúde Cubano, aponta que os médicos cubanos possuem perfil profissional generalista, consoante com a atenção primária no Brasil. Assim, segundo Medeiros ${ }^{41}$, em alguns casos, as críticas ao trabalho dos estrangeiros aproximam-se da xenofobia.

Além do mais, é necessário destacar que a formação médica brasileira difere em inúmeros aspectos da formação cubana, e talvez seja essa situação que propicie certo 'estranhamento'. Para Souza (2014), a formação médica brasileira volta-se para grandes centros médicos com tecnologia sofisticada e avançada. Tal característica difere do processo formativo vivenciado pelos médicos cubanos e é destacada nas matérias analisadas como um elemento que pode desqualificar o trabalho destes, focalizado na atenção primária. Entretanto, alguns estudos $\mathbf{4 2 , 4 3}^{4}$ apontam que são justamente os médicos 
brasileiros que não têm tido uma formação adequada ao perfil e às necessidades do SUS, implicando o desempenho insatisfatório identificado nos serviços públicos de saúde, especialmente para a atenção primária.

Trabalhos semelhantes ao apresentado neste artigo possuem resultados que corroboram os aqui analisados. Tais estudos destacam que as críticas ao PMM se concentram, principalmente, na abertura de novas vagas nos cursos de medicina - gerando, segundo os entrevistados, uma "precarização na formação médica", visto que, segundo eles, "em diversas localidades, não há serviços de saúde adequados para o desenvolvimento das práticas de ensino", bem como "não existe corpo docente qualificado". No que se refere à vinda de médicos estrangeiros, vários artigos que analisam as publicações da mídia apontam a reação negativa das entidades e de médicos entrevistados com relação a não exigência de revalidação do diploma, que "poderia gerar enormes consequências para os pacientes", uma vez que "não se sabe a capacidade técnica e clínica dos profissionais estrangeiros", apontando-se, também, as possíveis consequências negativas para o mercado de trabalho, visto que, segundo os críticos, "não haveria necessidade de novos médicos no Brasil", considerando-se que há uma repetição das políticas de interiorização médica no Brasil, que se centram apenas na falta de profissionais e negligenciam aspectos fundamentais, como a infraestrutura adequada para o exercício profissional e uma possível carreira médica no SUS $15, \mathbf{4 1 , 4 4}$.

Finalmente, cabe destacar que algumas investigações apresentam como resultado a relação entre o discurso negativo acerca do PMM e as críticas ao governo do Partido dos Trabalhadores (PT), particularmente na figura da ex-presidente Dilma Rousseff, o que demonstra o grau de politização conferido ao PMM, que se tornou, no período estudado, um dos principais alvos das forças contrárias às políticas sociais implementadas no período $2003-2013^{13,15}$.

Assim, é notório que, apesar de todas as discussões e críticas em torno da criação e da implementação do PMM, principalmente por parte das EM, o Programa representa um grande avanço em termos de política pública, que integra em uma única proposta elementos voltados ao provimento emergencial de médicos, à educação médica e ao desenvolvimento da infraestrutura das unidades de saúde no âmbito do SUS. Entretanto, faz-se necessária uma avaliação processual dos seus impactos, seja no processo formativo dos futuros profissionais ou na qualidade dos serviços prestados.

As evidências produzidas pelo estudo de Soares et al. ${ }^{45}$ mostram que as EM posicionaram-se contra o PMM, particularmente, quando o Programa contrariava os interesses da categoria médica, evidenciando, portanto, a manutenção dos interesses coorporativos de um segmento profissional pouco compromissado com o sistema público de saúde, afastando-se dos princípios e das diretrizes da RSB e do SUS.

Apesar do pequeno número de artigos que tratam desse tema, ou seja, com este recorte, o material analisado evidencia que a mídia atua simultaneamente como espaço de reverberação do debate político e, também, como um ator político que influi na opinião pública acerca do Programa. Desse modo, as notícias e outras publicações coletadas nos sites de EM e organizações governamentais evidenciam tomadas de posição diante das propostas do PMM, que, em última análise, expressam o alinhamento dessas organizações e entidades com projetos distintos com relação ao desenvolvimento do processo de construção do SUS, especialmente no que diz respeito ao fortalecimento da Atenção Primária à Saúde em municípios de pequeno porte e periferias das grandes cidades brasileiras. 


\section{Referências}

1. Brasil. Secretaria de Gestão do Trabalho e Educação na Saúde. Precarização e qualidade do emprego no Programa Saúde da Família. Brasília, DF: Ministério da Saúde; 2007.

2. Rodrigues PHA, Ney MS, Paiva CHA, et al. Regulação do trabalho médico no Brasil: impactos na Estratégia Saúde da Família. Physis. 2013; 23(4):11471166.

3. Starfield B. Atenção primária: equilíbrio entre necessidades de saúde, serviços e tecnologia. Brasília, DF: UNESCO; 2002.

4. Dal Poz MRA. A crise da força de trabalho em saúde. Cad. Saúde Pública. 2013; 29(10):1924-1926.

5. Machado MH. Os Médicos no Brasil: um retrato da realidade. Rio de Janeiro: Fiocruz; 1997.

6. Maciel Filho R, Branco MA. F. Rumo ao Interior: médicos, saúde da família e mercado de trabalho. Rio de Janeiro: Fiocruz; 2008.

7. Mancia JR. A enfermagem e o Programa de Interiorização do Trabalho em Saúde-PITS. Rev. Bras. Enferm. 2000; 53(3):341-342.

8. Campos CVA, Malik AM. Satisfação no trabalho e rotatividade dos médicos do Programa de Saúde da Família. Rev. adm. Pública. 2008; 42(2):347-368.

9. Brasil. Lei $\mathrm{n}^{\mathrm{o}} \mathbf{1 2 . 8 7 1}$, de 22 de outubro de 2013. Institui o Programa Mais Médicos, altera as Leis no 8.745, de 9 de dezembro de 1993, e $n^{\circ} 6.932$, de 7 de julho de 1981, e dá outras providências. Diário Oficial da União, 22 out 2013.

10. Magno LD. Dos clamores das ruas aos rumores no Congresso: uma análise da conjuntura recente da saúde no Brasil [dissertação]. Salvador: Universidade Federal da Bahia; 2015.

11. Rios DRS. Mapeamento da Produção científica so- bre o Programa Mais Médicos (2013-2016): contribuição ao debate sobre a atenção à saúde no SUS [monografia]. Salvador: Faculdade de Medicina da Bahia; 2017. 123 p.

12. Morais I, Alkmin D, Lopes J, et al. Jornais Folha de São Paulo e Correio Braziliense: o que dizem sobre o programa Mais Médicos?. Rev Esc Enferm USP. 2014; (48):107-115.

13. Segalin M. O Programa Mais Médicos: um estudo de imagem a partir da revista veja [monografia]. Porto Alegre: Universidade Federal do Rio Grande do Sul; 2013. 68 p.

14. Scremin L, Javorski E. O enquadramento das notícias sobre os estrangeiros no programa mais médicos. Cad. da Esc. de Com, 2013.

15. Souza L. Representação do programa MM pelo site do pragmatismo político e pelo portal do conselho federal de medicina [dissertação]. Brasília, DF: Departamento de Linguística, Universidade de Brasília; $2014.144 \mathrm{p}$.

16. Camurça LI. Um estudo sobre a relação entre a Democracia Digital e a Participação Política a partir do debate sobre o Programa Mais Médicos no Facebook. Revista Mídia e Cotidiano. 2014; 3(2):538-561.

17. Fontanella BJ, Ricas J, Turato ER. Amostragem por saturação em pesquisas qualitativas em saúde: contribuições teóricas. Cad. Saúde Pública. 2008; 24(1):17-27.

18. Maingueneau D. Novas tendências em Análise do Discurso. Campinas: Pontes; 1997.

19. Paim JS. A Constituição Cidadã e os 25 anos do Sistema Único de Saúde (SUS). Cad. Saúde Pública. 2013; 29(10):1927-1936.

20. O Globo. Na Saúde, Medidas Propostas por Dilma já não são Novas [internet]. 2013 jun. 24 [acesso em 
2018 jun 25]. Disponível em: https://oglobo.globo. $\mathrm{com} /$ brasil/na-saude-medidas-propostas-por-dilma-ja-nao-sao-novas-8801855.

21. Scheffer M. Demografia médica no Brasil. São Paulo: Departamento de Medicina Preventiva da Faculdade de Medicina da USP; Conselho Regional de Medicina do Estado de São Paulo: Conselho Federal de Medicina; 2015.

22. Folha de São Paulo. Paulo Capel Narvai: Ponto de Colisão [internet]. 2013 jul. 28 [acesso em 2018 jun 25]. Disponível em: http://wwwl.folha.uol.com.br/ opiniao/2013/07/1317816-paulo-capel-narvai-ponto-de-colisao.shtml.

23. Brasil. Portaria Interministerial MEC/MS no 278, de 17 de março de 2011, Brasília, DF: Diário Oficial da União; 2011.

24. Associação Brasileira de Saúde Coletiva. Mais médicos: programa atende a todas as necessidades prioritárias do SUS [internet]. 2013 jul. 12 [acesso em 2018 jun 25]. Disponível em: https://www. abrasco.org.br/site/noticias/sistemas-de-saude/ mais-medicos-programa-atende-a-todas-as-necessidades-prioritárias-do-sus/11047/.

25. Souza LEPF. A agenda atual da Reforma Sanitária Brasileira. Physis. 2014; 24(4):1017-1021.

26. Associação Brasileira de Saúde Coletiva. Melhor é tornar possível - Artigo de Ligia Bahia em O Globo [internet]. 2013 set. 16 [acesso em 2018 jun 25]. Disponível em: https://www.abrasco.org.br/site/noticias/sistemas-de-saude/melhor-e-tornar-possivel-artigo-de-ligia-bahia-em-o-globo/1244/.

27. Mancebo D, Vale AA, Martins TB. Políticas de expansão da educação superior no Brasil 1995-2010. Rev. Bras. Edu. 2015; 20(60):31-50.

28. Associação Brasileira de Saúde Coletiva. Brasil deveria focar menos em médicos e mais em enfermeiras, diz Ilona kickbusch [internet]. 2013 ago 7 [acesso em 2018 jun 25]. Disponível em: https://www. abrasco.org.br/site/noticias/sistemas-de-saude/ brasil-deveria-focar-menos-em-medicos-e-mais-em-enfermeiras-diz-ilona-kickbusch/1147/.

29. O Globo. Entidades médicas condenam programa "Mais Médicos" [internet]. 2013 jul 8 [acesso em 2018 jun 25]. Disponível em: http://gl.globo.com/ bemestar/noticia/2013/07/entidades-medicas-condenam-programa-mais-medicos.html.

30. Teixeira CF, Vilasbôas ALQ. Modelos de Atenção à Saúde no SUS: Transformação, Mudança ou Conservação? In: Paim JS, Almeida Filho N, organizadores. Saúde Coletiva: teoria e prática. Rio de Janeiro: Med Book, 2014. p. 287-302.

31. Silva LASR. A educação médica e a reforma sanitária. Cad. Saúde Pública. 1986; 2(4):493-504.

32. Amoretti R. A Educação Médica diante das Necessidades Sociais em Saúde. Revista brasileira de educação médica. 2005; 29 (2):136-146.

33. Póvoa EC. Corporativismo e medicina contemporânea. In: Mello Filho J, organizador. Identidade Médica. São Paulo: Casa do Psicólogo; 2006. p. 371-390.

34. Teixeira CF, Souza LE, Paim JS. Sistema Único de Saúde (SUS): a difícil construção de um sistema universal na sociedade brasileira. In: Paim JS, Almeida-Filho N, organizadores. Saúde Coletiva: teoria e prática. Rio de Janeiro: Medbook; 2014. p. 121137.

35. Paim JS. Reforma Sanitária Brasileira: avanços, limites e perspectivas. In: Matta GC, Lima JCF, organizadores. Estado, Sociedade e Formação Profissional em Saúde. Rio de Janeiro: Fiocruz; 2008. p. 91-122.

36. De Medeiros KR, Tavares RAW. Questões contemporâneas da gestão do trabalho em saúde: em foco, a Lei de Responsabilidade Fiscal. Divulgação em Saúde para Debate, 2012; (47):56-64.

37. Campos FE, Machado MH, Girardi SN. A fixação de profissionais de saúde em regiões de necessidades. Divulgação em Saúde para Debate. 2009; (47):13-24. 
38. Mendonça MHM, Martins MIC, Giovanella L, et al. Desafios para gestão do trabalho a partir de experiências exitosas de expansão da Estratégia de Saúde da Família. Ciênc. Saúde Colet. 2010; 15(5):23552365.

39. Junqueira TS, Cotta RMM, Gomes RC, et al. A Gestão do Trabalho e o Contexto da Flexibilização no Sistema Único de Saúde. Divulgação em Saúde para Debate. 2012; (47):33-44.

40. Madureira PSP. Sistema de Saúde Cubano [dissertação]. Coimbra (Portugal): Faculdade de Medicina da Universidade de Coimbra; 2010.

41. Medeiros ES. A motivação de médicos cubanos em uma política pública brasileira: a xenofobia e interferência na qualidade dos serviços. Anais do XI Simpósio de Excelência em Gestão e Tecnologia, 2014.
42. Pierantoni CR. As reformas do Estado, da saúde e recursos humanos: limites e possibilidades. Ciênc. Saúde Colet. 2001; 6(3):341-360.

43. Pierantoni CR, Varella TC, Santos MR, et al. Gestão do trabalho e da educação em saúde: recursos humanos em duas décadas do SUS. Physis. 2008; 18(4):685-704.

44. Terra LSV, Borges TF, Lidola M, et al. Análise da experiência de médicos cubanos numa metrópole brasileira segundo o Método Paidéia. Ciênc. Saúde Colet. 2016; 21(9):2825-2836.

45. Soares CLM, Freitas MS, Teixeira CF, et al. Análise do Posicionamento das Entidades Médicas - 20152016. Saúde debate. 2017; 41(esp. 3):74-86.

Recebido em 26/10/2017

Aprovado em 18/03/2018

Conflito de interesses: inexistente

Suporte financeiro: não houve 